\title{
Phosphatidylserine Antibody IgM Measurement
}

National Cancer Institute

\section{Source}

National Cancer Institute. Phosphatidylserine Antibody IgM Measurement. NCI

Thesaurus. Code C122145.

The determination of the amount of phosphatidylserine antibody Ig M present in a sample. 